\title{
GENETICS OF SHELL GROUND COLOUR IN HELIX ASPERSA \\ II. ALBINO, ITS MUTATIONS AND INTERACTIONS
}

\author{
R. M. ALBUQUERQUE DE MATOS \\ Center of Genetics and Molecular Biology, Ave. Prof. Gama Pinto 2, \\ 1699 Lisbon Codex, Portugal
}

Received 4.xi.83

\section{SUMMARY}

\begin{abstract}
Albino shells, devoid of pigment in their calcareous part and with a pale yellowish periostracum, occur in natural populations of Helix aspersa, and in our cultures seven spontaneous mutations have been detected. Five of these have been tested as to genetic homology and two are still young. All five mutants proved to have the same $a$ recessive allele as the two foundation albinos from natural populations so that the mutation rate is extremely high. Albino and the ground shell colour locus $C$ are distinct and not linked. In double recessive form albino inhibits colours due to $C$ and also the uniformly distributed reddish dark brown colour due to $U$. Other effects of $U$, suppression of bands and of structural markings are not affected by albino. In single dose $a$ is completely recessive as to effects on $C$ but $\operatorname{AaU}(U, u)$ heterozygotes show attenuation of epistasis of $U$ colour over that due to $C$ alleles. Making use of this effect, it is shown that $U$ and $a$ are not linked. The locus $M$ for intensity of band pigmentation is not linked to $a$ and apparently also not to $U$.
\end{abstract}

\section{INTRODUCTION}

The albino condition is relatively frequent in Helix aspersa. It occurs in natural populations and we have obtained it repeatedly by spontaneous mutation in our cultures. Albino shells have a completely non-pigmented calcareous part, covered by a light yellowish periostracum which may become more or less tanned in aged adults, so that in the absence of well pigmented bands close observation, especially at successive stages during shell growth, may be necessary to distinguish albino from lightly pigmented shells. However, in general the distinction is easy at hatching in broods where albinos and pigmented segregate. If bands are present they may be in albino shells completely depigmented and translucent (hyalozonate) or more or less lightly coloured by an orange pigment. Living albinos may appear greenish because of their dark mantle being seen through the noncoloured or lightly yellowish shell.

It has been shown (Stelfox, 1915, 1918; Cook, 1969, interpreting results obtained by Diver; for reviews cf. Murray, 1975 and Clarke et al. 1978) that in aspersa albino is due to a recessive. This mode of inheritance is corroborated by results here presented in continuation of previous work where the notation $A-a$ for the albino locus has been proposed (Aluuquerque de Matos, 1979, 1982). Of course, there is no assurance that the albinos we study are due to the same gene as the albino previously reported by Stelfox or that mentioned by Cook, since similar phenotypes may appear by mutation at different loci. Results presented here show that in five mutants albino is due to the same or a similar allele of a single locus. Other new results 
reported here show that the albino locus is distinct from and unlinked to the other ground shell colour loci, $C$ and $U$ (for these cf. the first paper of this series) and display interactions between the albino allele in single or double dose and $U$ or $U$ and $C$, as also between albino and banding.

\section{LINES AND METHODS}

Isolation of lines and culture methods have been described in previous work (Albuquerque de Matos, 1982, 1984).

Albino mutants are detected soon after hatching, when the first scoring of segregating phenotypes is made. They are distinctly lighter than the pigmented sibs, in which in some cases it is already possible to distinguish more than one hue. Scoring is repeated at periodical intervals and albino mutants are then confirmed. The lines derived from these mutants are denoted A, as albino lines in general, Roman numerals corresponding to order of mutant detection.

Testing procedures of the several albino mutants are indicated when each of them is discussed. Remating to virgin snails of one or the two parents of crucial matings is included in these procedures. In such cases the broods produced by the virgin parent only are considered.

\section{Albino homology AND mUtational origin}

Two albino adult snails were obtained from a local population of aspersa present in a Lisbon market. Mating of these snails (mating 53, table 1) yielded albinos and pigmented. The pigmented must have resulted from previous matings in the wild. Sib matings followed: pigmented by albino (mating 239), albinos by albinos (240) and pigmented by pigmented (254). Results of these matings proved that a single locus for albino was involved and that the two albino alleles present in the two mates of 53 were homologous ( $\chi^{2}$ for matings 239 and 254 , respectively 0.025 and 0.183 , $P=0.87$ and 0.67 ). The mass mating between albinos produced albinos only. Albinos from the progeny of 53 were the origin of line A.I, used as standard albinos in our study.

Other albinos tested, as shown in table 1, are A.II, A.III and A.VI. The first of these segregated in sib crosses derived from mating 101 in line L.II-2 (line L.II was derived from a brood of an adult snail collected in a Lisbon garden and 101 is a sib mating from the offspring of two snails pertaining to this brood). One of the mates of cross 101 certainly carried a mutation from pigmented to albino, so that in the $F_{2}$ typical $3 / 4$ to $1 / 4$ segregations of pigmented to albinos appeared (discussion in Albuquerque de Matos and Serra, 1982). Mating 285 shows one of these segregations $(P=0.24)$; matings 427 and $465(P=0.64)$ refer also to mutant A.II. Matings 452, 551 and 768 were intended to probe for homology between A.II and the standard A.I. The results show that the two albino alleles belong to the same locus $(P=0.74$ and 0.40 , respectively).

Similar tests for homology with A.I of A.III and A.VI are also shown in table 1 , matings 758 and $727 . R(P=0.31$ and 0.48 , respectively), and mating $835(P=0.73)$ tests directly the homology between A.II and A.III. The origin of this latter is shown in table 1: mating 391, between two unrelated pigmented snails of two lines derived from different specimens 
TABLE 1

Some of the matings of Helix aspersa made to probe for monogenicity of albinos A.I, A.II, A.III and A.VI and to establish their homology. Provenance: C Coimbra, L Lisbon. Pigt het pigmented heterozygous for. mut. a mutant. Prog. progeny (of mating No....)

\begin{tabular}{|c|c|c|c|c|}
\hline \multirow[b]{2}{*}{$\begin{array}{l}\text { Mating } \\
\text { No. }\end{array}$} & \multicolumn{2}{|c|}{ Parents } & \multicolumn{2}{|c|}{ Progeny } \\
\hline & Provenance & Phenotype & Phenotype & $\begin{array}{l}\text { Number } \\
\text { observed }\end{array}$ \\
\hline 53 & $\begin{array}{l}\text { Lisbon (market } \\
\text { Lisbon (market) }\end{array}$ & $\begin{array}{l}\text { Albino } \\
\text { Albino }\end{array}$ & $\begin{array}{l}\text { Albinos A.I } \\
\text { Pigmented }\end{array}$ & $\begin{array}{r}385 \\
33\end{array}$ \\
\hline 239 & $\begin{array}{l}\text { Prog. } 53 \\
\text { Prog. } 53\end{array}$ & $\begin{array}{l}\text { Albino } \\
\text { Pigmented }\end{array}$ & $\begin{array}{l}\text { Albinos } \\
\text { Pigmented }\end{array}$ & $\begin{array}{l}179 \\
176\end{array}$ \\
\hline 240 & $\begin{array}{l}\text { Prog. } 53 \\
\text { (mass mating) }\end{array}$ & Albinos & Albinos & 384 \\
\hline 254 & $\begin{array}{l}\text { Prog. } 53 \\
\text { Prog. } 53\end{array}$ & $\begin{array}{l}\text { Pigmented } \\
\text { Pigmented }\end{array}$ & $\begin{array}{l}\text { Albinos } \\
\text { Pigmented }\end{array}$ & $\begin{array}{r}43 \\
139\end{array}$ \\
\hline 285 & $\begin{array}{l}\text { L.II-2 (prog. 101) } \\
\text { L.II-2 (prog. 101) }\end{array}$ & $\begin{array}{l}\text { Pigmented } \\
\text { Pigmented }\end{array}$ & $\begin{array}{l}\text { Albinos A.II } \\
\text { Pigmented }\end{array}$ & $\begin{array}{l}107 \\
365\end{array}$ \\
\hline 427 & $\begin{array}{l}\text { Prog. } 285 \\
\text { (mass mating) }\end{array}$ & Albinos & Albinos & 93 \\
\hline 465 & $\begin{array}{l}\text { Prog. } 285 \\
\text { Prog. } 285\end{array}$ & $\begin{array}{l}\text { Albino } \\
\text { Pigmented }\end{array}$ & $\begin{array}{l}\text { Albinos } \\
\text { Pigmented }\end{array}$ & $\begin{array}{l}84 \\
78\end{array}$ \\
\hline 391 & $\begin{array}{l}\text { C.III-1 } \\
\text { C.III-2 }\end{array}$ & $\begin{array}{l}\text { Pigmented } \\
\text { Pigmented }\end{array}$ & $\begin{array}{l}\text { Albino (mut. A.III) } \\
\text { Pigmented }\end{array}$ & $\begin{array}{r}1 \\
80\end{array}$ \\
\hline 457 & $\begin{array}{l}\text { Prog. 391 } \\
\text { Prog. } 391\end{array}$ & $\begin{array}{l}\text { Albino A.III } \\
\text { Pigmented }\end{array}$ & Pigmented & 20 \\
\hline 708 & $\begin{array}{l}\text { Prog. } 457 \\
\text { Prog. } 457\end{array}$ & $\begin{array}{l}\text { Pigmented } \\
\text { Pigmented }\end{array}$ & $\begin{array}{l}\text { Albinos } \\
\text { Pigmented }\end{array}$ & $\begin{array}{r}87 \\
247\end{array}$ \\
\hline 452 & $\begin{array}{l}\text { Prog. } 285 \\
\text { Prog. } 349 A\end{array}$ & $\begin{array}{l}\text { Albino A.II } \\
\text { Pigt het A.I }\end{array}$ & $\begin{array}{l}\text { Albinos } \\
\text { Pigmented }\end{array}$ & $\begin{array}{l}40 \\
43\end{array}$ \\
\hline 551 & $\begin{array}{l}\text { Prog. } 349 A \\
\text { Prog. } 282\end{array}$ & $\begin{array}{l}\text { Albino A.I } \\
\text { Pigt het A.II }\end{array}$ & $\begin{array}{l}\text { Albinos } \\
\text { Pigmented }\end{array}$ & $\begin{array}{l}22 \\
28\end{array}$ \\
\hline 758 & $\begin{array}{l}\text { Prog. } 485 \\
\text { Prog. } 457\end{array}$ & $\begin{array}{l}\text { Albino A.I } \\
\text { Pigt het A.III }\end{array}$ & $\begin{array}{l}\text { Albinos } \\
\text { Pigmented }\end{array}$ & $\begin{array}{l}43 \\
53\end{array}$ \\
\hline 727.R & $\begin{array}{l}P_{1} \text { of } 727 \\
\text { Prog. } 525\end{array}$ & $\begin{array}{l}\text { Albino mut. A.VI } \\
\text { Pigt het A.I }\end{array}$ & $\begin{array}{l}\text { Albinos } \\
\text { Pigmented }\end{array}$ & $\begin{array}{l}14 \\
18\end{array}$ \\
\hline 768 & $\begin{array}{l}\text { Prog. } 417 \\
\text { Prog. } 479\end{array}$ & $\begin{array}{l}\text { Albino A.II } \\
\text { Albino A.I }\end{array}$ & Albinos & 20 \\
\hline 835 & $\begin{array}{l}\text { Prog. } 465 \\
\text { Prog. } 457\end{array}$ & $\begin{array}{l}\text { Albino A.II } \\
\text { Pigt het A.III }\end{array}$ & $\begin{array}{l}\text { Albinos } \\
\text { Pigmented }\end{array}$ & $\begin{array}{l}35 \\
38\end{array}$ \\
\hline
\end{tabular}




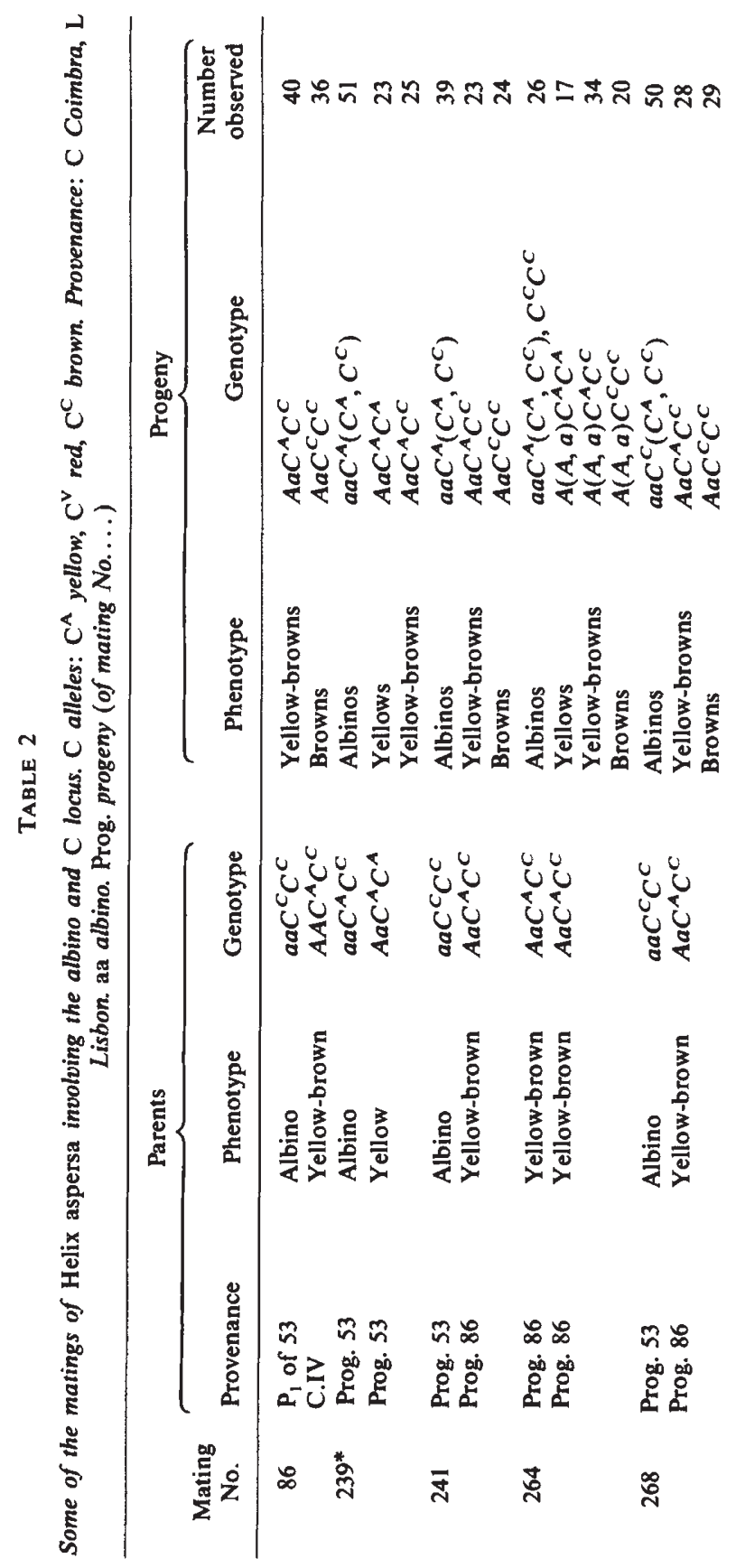




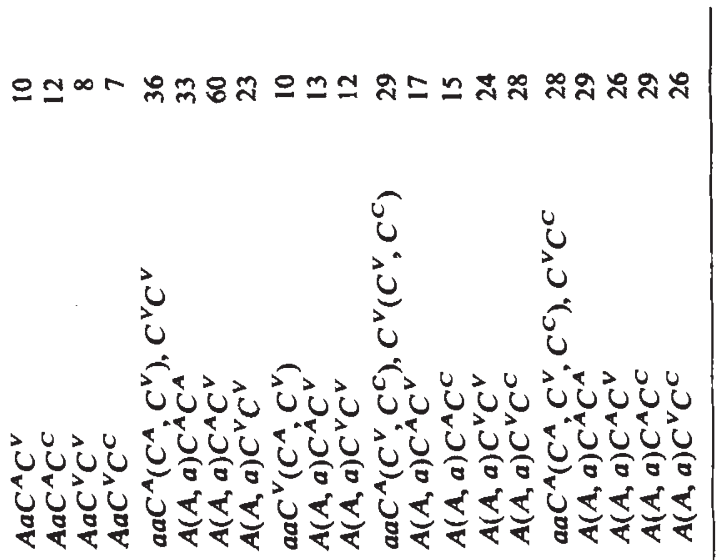

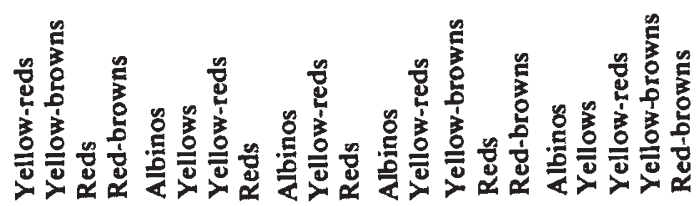

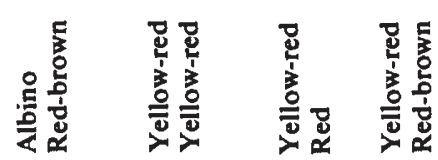

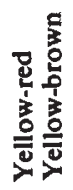

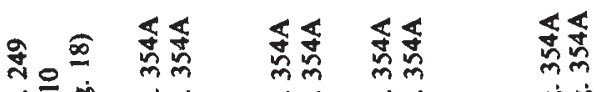

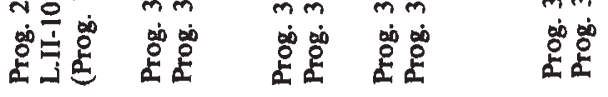

㐫

$\stackrel{\infty}{\curvearrowleft}$

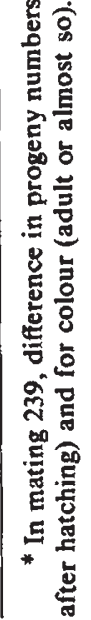


Mutations to albino. Besides the two original A.I albinos, seven others, which must have each appeared by mutation, have been detected in our cultures. Of these mutants three have been tested for homology, two others died before adult age and the other two are still young. The two which died appeared in progenies of matings 407 and 409 (cf. table 3). In the first of these matings one parent was heterozygous for albino A.I and in the second one parent was an albino A.I. In both matings the other parent was homozygous pigmented, from two different pigmented lines. If the mutant albinos were recessive, as in all the cases tested they are, each mutant should have resulted from the union of a gamete bearing $a$ produced in the heterozygous $A a$ parent (407) or in the homozygous aa parent (409) and a gamete with a mutation $A \rightarrow a$ from the homozygous pigmented mate. In these conditions, appearance of one albino indicates that a mutation has generated an $a$ allele homologous to the A.I locus.

The heterozygosity of one of the mates in other crosses which produced a mutant albino was tested in the case of A.VI: both mates of 495 were remated to albinos A.I, one of the resulting progenies consisting of pigmenteds only and the other of albinos and pigmenteds. Mutations A.II and A.III have been considered in a paper (Albuquerque de Matos and Serra, 1982) on the rate of mutation of the albinos and other loci in $H$. aspersa, the other mutants mentioned here are new. The rate of mutation to albino was estimated to be $1.2 \times 10^{-3}\left[95\right.$ per cent limits $\left.(0.03-6.5) \times 10^{-3}\right]$. Estimation of a more precise rate, considering the new mutants, will be made in subsequent work.

It is remarkable that all $a$ factors tested are homologous, belonging to the same locus. It thus appears that in $H$. aspersa a single locus has the possibility of mutating to albino or, if other loci share this property, their mutations must be rarer than that of the $A$ - $a$ locus here considered.

\section{Albino AND GRound SHEll COLOUR LOCI: Distinction AND INDEPENDENT SEGREGATION}

Results in table 2 provide evidence on the distinction between albino and the ground shell colour locus $C$ discussed in the previous paper of this series. Other results in the table are informative on whether these loci are linked or segregate independently. If $a$ was a recessive allele of $C$ (say $C^{a}$ ), mating an albino to a yellow-brown (as in 86 , broods laid by the pigmented only being considered) would give a progeny with two classes, yellow and brown separately, which was not the case, yellow-browns; and browns being produced, in $1 / 2$ to $1 / 2$ segregation $(P=0.65)$. For the observed progeny to be produced the albino parent in 86 , which was the same as $P_{1}$ in cross 53 of table 1 , must have had two hidden alleles $C^{C} C^{C}$ for brown. Yellowbrowns which can be distinguished with certainty from browns and from yellows usually appear in line C.IV to which the $P_{2}$ of cross 86 belongs. However, confirmation of the interpretation of hidden $C$ alleles in the original $P_{1}$ albino, and on the nature of similar alleles which should be present in the other mate of the original cross 53, would be desirable. Matings 239 through 268 provide evidence on these points, indicating that the $\mathrm{P}_{2}$ mate in 53 should have $C^{A} C^{C}$ hidden alleles and further that it probably had been fertilised by some other albino or heterozygous of albino. The two mates of 53 were not virgin and produced, besides albinos, five 
browns, 26 yellow-browns and two yellows. One of these yellows is the $\mathrm{P}_{2}$ of 239.

The distinction between the two loci, $A-a$ and $C$, is further demonstrated by the series of matings $354 \mathrm{~A}$ through 588 , where albinos plus four colour classes segregate. This would be impossible if $a$ was a recessive allele of $C$, in which case at the most three colour classes plus albino could segregate. The series of ten crosses of table 2 , set up so as to provide in due time results for the computation of the cross-over value if the two loci would prove to be linked, are interpreted as to genotypes as shown in the table. $C$ alleles of the pigmenteds are directly derived from the observed phenotypes and the hidden $C$ alleles of the albino mates are deduced from the progenies. For every cross listed, numbers obtained agree well with those expected without linkage between $A-a$ and $C$ ( $P$ for independent segregation, by order of crosses listed in the table and considering all the classes in each progeny, $0.65,0.92,0.68,0.91,0.79,0.66,0.57,0.87,0.27$ and 0.74$)$.

\section{ALBINO-UNIFORM INTERACTIONS AND INDEPENDENT SEGREGATION}

Results presented in table 2 show that in every case in which pigmented are $A a$, heterozygous for albino, the phenotype is indistinguishable from that of the respective $A A$ homozygote. For example, in the progeny of 239 the genotype of yellows is indicated as $A(A, a) C^{A} C^{A}$, meaning that $A A C^{A} C^{A}$ homozygotes have the same phenotype as $A a C^{A} C^{A}$ heterozygotes. Rather unexpectedly we have observed that, when albino and uniform are present together in a genotype the colour due to $C$ alleles becomes apparent by attenuation of the reddish dark brown colour characteristic of uniform. This was observed first in the case of combinations of $a$ and $U$ with lighter $C$ alleles, especially yellow, but then closer observation showed that the effect is extendable to other $C$ alleles. Thus the epistasis of $U$ over $C$ (cf. previous paper of this series) is attenuated by the presence of $a$, so that uniform as to shell structure and band suppression may then be classified in colour classes parallel to the classes of the banded in the same progeny. Epistasis attenuation is more marked in $U u$ heterozygotes than in $U U$ homozygotes.

Table 3 shows two related series of crosses, one beginning with mating 145 , the other with 328 , set up to clarify the effect of heterozygous albino on $U$ epistasis over $C$ alleles. The matings were also aimed at determining the cross-over value between $A-a$ and $U-u$ in case linkage between these loci. In the previous section it has been shown that $A-a$ and $C$ are not linked, and in the previous paper the same was shown with respect to $C$ and $U$ - $u$.

In mating 145 the same albino $P_{1}$ of 53 and $P_{1}$ of 86 (cf. tables 1 and 2) was again remated to a typical reddish dark brown uniform from L.IV. All the progeny (broods laid by the pigmented only) were characteristically uniform as to shell structure and band absence, but two different classes of reddish browns, one darker than the other, could be distinguished, as is indicated in the table. Numbers agree well with an $1 / 2$ to $1 / 2$ segregation $(\mathrm{P}=0.54)$. The following mating 249 , of an albino progeny of 53 by a uniform reddish medium brown progeny of 145 , yielded banded and unbanded albinos, plus banded and uniforms of two easily scorable classes, yellow-red and yellow-brown. Uniforms and banded of the two colour 


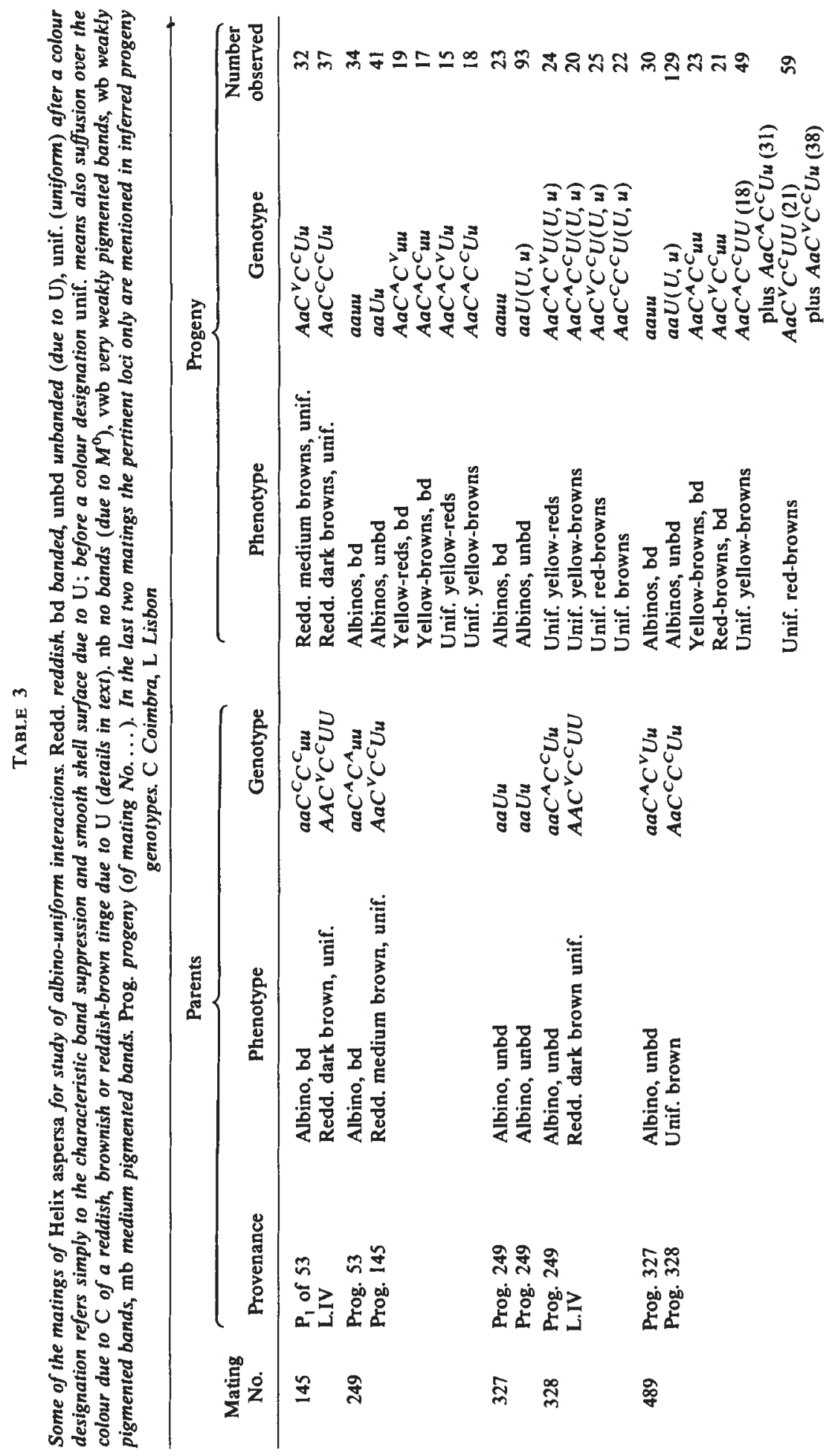




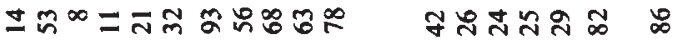

ㅇ

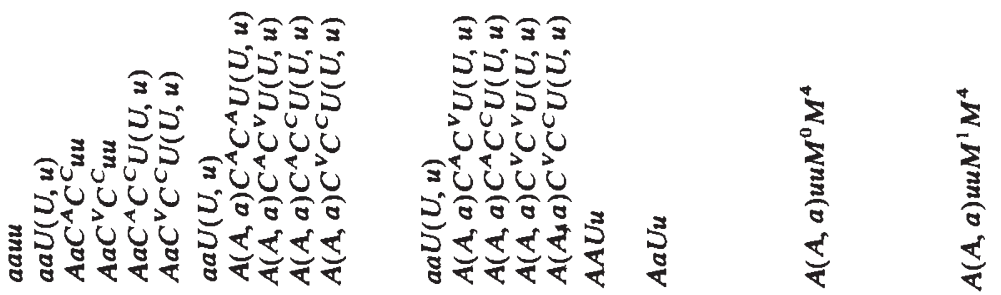

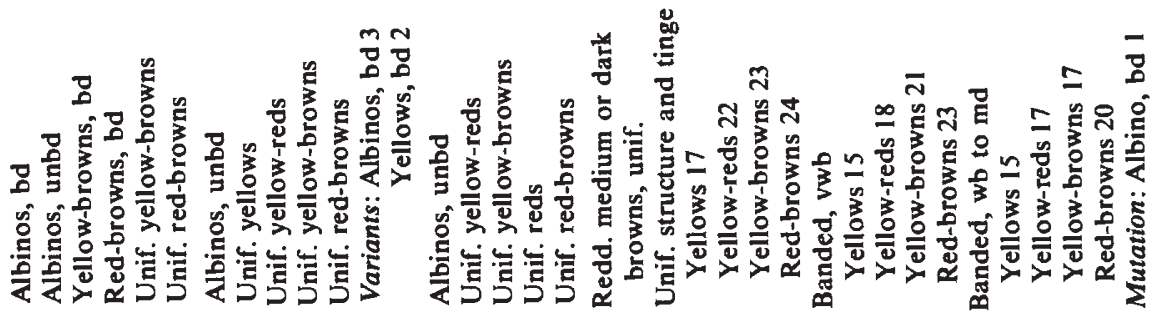

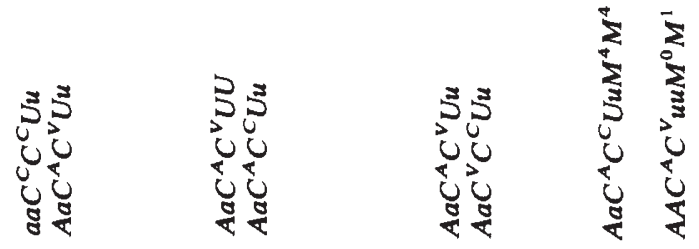

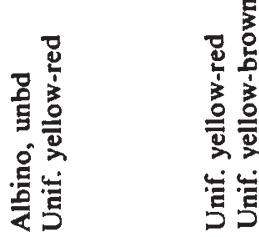

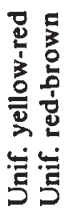

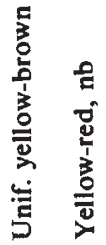

\begin{tabular}{|c|c|c|c|}
\hline 昏 స్ల & 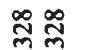 & స్లి స్లి & gे \\
\hline 定 & 总 & $\begin{array}{l}\text { co } \\
\text { 일 } \\
\text { D. }\end{array}$ & 定 \\
\hline$\pi$ & สี & $\tilde{\tilde{n}}$ & g \\
\hline
\end{tabular}




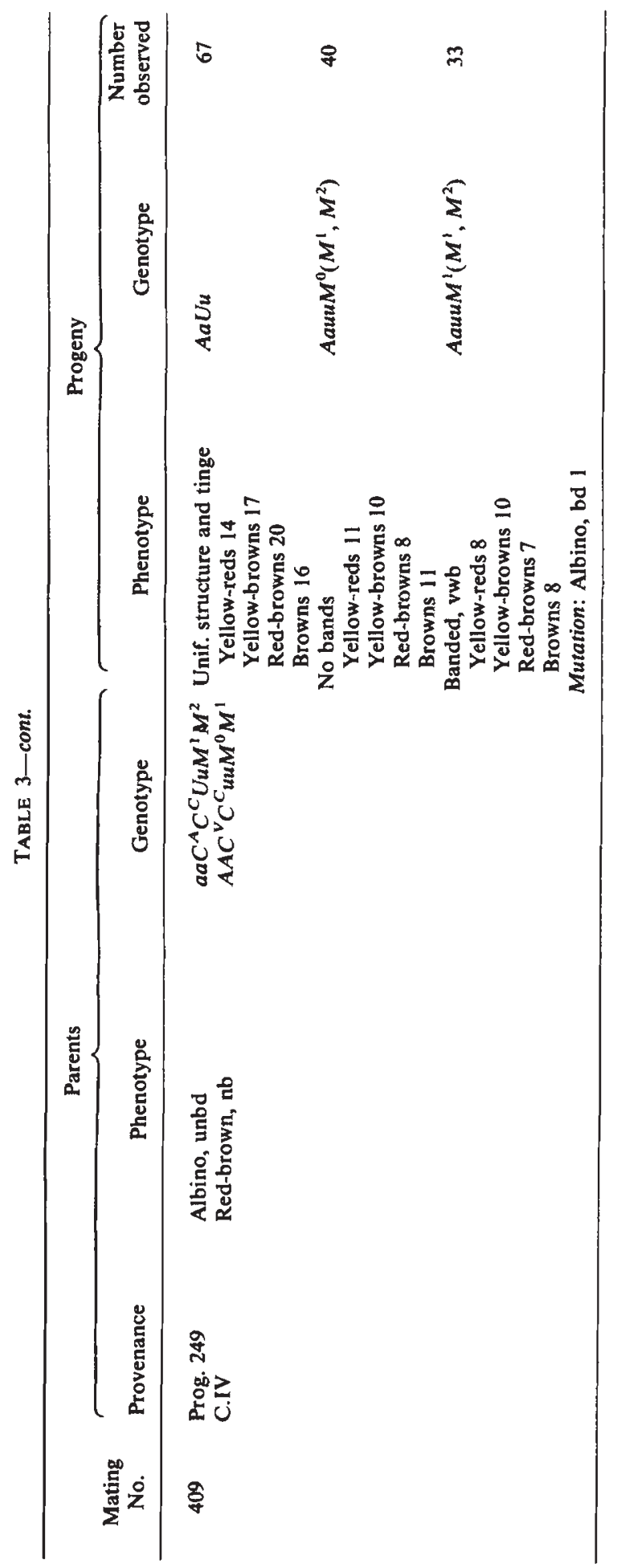


classes differ in that the uniforms show a distinctive reddish brown, or more markedly reddish brown, tinge.

Albinos are in this case, as all through the table, scored simply as banded and unbanded because uniform, which is expressed in them as well as in pigmented, often does not produce a shell structure much different from that of the usual non-uniform albinos, which may not have bands and may show a rather homogeneous shell structure. Certainly, a large fraction or almost all of the 41 albinos without bands in the progeny of 249 are uniforms: segregation $1 / 2 U u$ without bands to $1 / 2 u u$ with bands is not contradicted by the numbers observed $(P=0 \cdot 42)$. Mating 327 , between two unbanded albinos progeny of 249 , was intended to test the interpretation that band absence in albinos is in this series of matings practically in every case due to the presence of $U$. About $1 / 4$ banded to $3 / 4$ unbanded segregate $(P=0.20)$ because alleles for strong bands are present in the genotype. If alleles for weak bands were instead present, more albinos could be unbanded. Results of this mating, together with those of the other crosses of the two series, may be interpreted as implying independent segregation between $A-a$ and $U$ - $u$.

The genotypes attributed to mates and progenies in crosses 145 and 249, as well as in subsequent crosses in table 3 , are inferred directly from the observed phenotypes, or are derived from previous results expressed in table 2 (cf. matings 86 and 354A there). Attenuation of $U$ epistasis over $C$ is apparent in the progeny of 145 , but the difference relative to the colour of typical uniforms is not as marked in this case as is in the progeny of 249 , where $C^{A}$, for yellow, is present in the genotype.

Mating 328 is the first where $U U$ and $U u$ occur together in colour classes which should be scorable because all the progeny must be $A a$. An unbanded albino definitely heterozygous for $U$, progeny of 249 , was mated to a typical L.IV reddish dark brown uniform which should be homozygous for $U$. The progeny consisted of uniforms only but four colour classes could be scored, with numbers and inferred genotypes as is shown in the table $(\mathrm{P}=0.89$ ). Parental genotypes as to $C$ were derived from those of the progeny. About one half of each class showed a more marked reddish brown tinge, which probably would correspond to $U U$ homozygotes, but distinction between these and the heterozygotes was not attempted in this case.

Of the four matings which follow, two of them are equivalent to backcrosses, one of the parents being an unbanded albino; the other two are $F_{1} \times F_{1}$ of 328 . Banded classes in the progeny of 489 show strongly pigmented bands which are characteristic of L.IV. Owing to the presence in the genotype of alleles for strongly pigmented bands it is possible to distinguish in the two uniform classes $U U$ homozygotes from $U u$ heterozygotes. These latter show band vestiges in the form of melanic spots near the shell aperture. Such spots are absent in $U U$ homozygotes, which in general have a more marked reddish brown tinge than the corresponding heterozygotes. This distinction is not possible in the albinos of the progeny, which nevertheless also clearly show bands in about $1 / 4$ of the number that segregated in this class (for $1 / 4$ to $3 / 4, P=0 \cdot 07$, indicating incomplete penetrance in the manifestation of bands). Bands in albinos were in 28 shells hyalozonate passing to slightly orange pigmented in their last third, and in two shells there were exclusively orange pigmented delayed bands. Inferred genotypes are shown in the table and the observed numbers agree well with the 
interpretation proposed, which includes independence of the three loci involved in the segregation (for all eight classes, $P=0.54$ ). It may be remarked that the strong bands characteristic of L.IV which come with $U$ pass to the non-uniform albinos, as well as to the non-uniform pigmented, indicating that the locus $M$ which determines intensity of band pigmentation (cf. previous paper) segregates independently of the other loci involved in this mating.

The albino mate of $521 \mathrm{~A}$ is from the progeny of $394 \mathrm{~A}$ (sib mating, progeny of 249). The results are similar to those of 489 just discussed, but in $521 \mathrm{~A}$ the banded classes show weakly pigmented bands which must have come from the initial albinos of 53. Owing to this characteristic it was not possible to distinguish in the progeny $U U$ homozygotes from $U u$ heterozygotes. In each of the three colour classes there is nevertheless good agreement with a segregation $1 / 4$ banded to $3 / 4$ unbanded due to $U U$ or $U u$ (for all six classes, $\mathrm{P}=0.60$ ).

The results of 522 and 523 confirm the genotypes attributed to the parents and progeny classes of 328 . In both matings albinos plus four colour classes segregated. An apparent excess of red-browns appeared in the progeny of 522 , but agreement with the expected segregation for equal numbers in these four classes is still reasonable $(P=0.41)$. An excess of red-browns could result from the reddish brown tinge due to $U U$ homozygotes present in the other colour classes. In this progeny $U u$ heterozygotes could not be distinguished through their band vestiges from $U U$ heterozygotes.

Both mates of 522 were tested as to their genotype with respect to $U$, the $\mathrm{P}_{1}$ being homozygous $U U$ and the other heterozygous $U u$. The virgin tester snails were from a yellow strain (C.III) with strongly pigmented bands. This test has been made because in one brood of the progeny of 522 three banded albinos plus two yellows with strongly pigmented bands appeared. This result very probably implies change from $U$ to $u$ in the gametes produced by the $U U$ parent which gave origin to the five exceptional progeny; or a corresponding change from $U$ to $u$ in the $U u$ zygotes occurred. This point will be discussed in other work.

Mating 523 is similar to the preceding one, but both parents should be $U u$ because very weak or vestigial bands appeared in a fraction of the progeny in the four colour classes. Albinos did not show such vestiges. Because many of the vestiges are difficult to distinguish from a fully unbanded condition, no attempt is made here to present numbers for each of the banding possibilities. The heterozygous $U u$ constitution of the parents was also indicated by the fact that in each colour class about one third of the shells showed a more accentuated reddish brown tinge, characteristic of $U U$ homozygotes, than the other two thirds. Numbers in each class agree well with expectation for the proposed genotypes and independent segregation of the three loci inolved (for the five classes $P=0 \cdot 81$ ).

Two matings, 407 and 409 , at the bottom of table 3 are intended to provide information on banding relative to $U$ so as to determine whether or not this locus is linked to $M$. Scoring, of prepared shells with their banding terminated, referred basically to this trait but ground colour was also recorded. For surer conclusions on linkage between $M$ and other characters, extreme degrees of band pigmentation are preferably to be used, but $M^{0}$ for no bands or only very weakly pigmented bands may be confused with unbanded due to $U$ if shell surface does not present structural markings. 
Heterozygous albino must be included in the genotype so that colour classes may be scored in uniforms as in those unbanded without $U$. The two crosses here included obey these conditions, relatively strongly pigmented bands segregating in one of them and weakly pigmented bands in the other.

In mating 407 a heterozygous $A a U u$, progeny of 249 , was mated to an unbanded yellow-red (line L.II). The uniform $P_{1}$ mate could have $M$ alleles for strongly pigmented bands, which were present in the banded progeny of 249. The unbanded $\mathrm{P}_{2}$ mate should be $M^{0} M^{0}$ or $M^{0} M^{1}$, this second constitution being more likely according to the results observed in the line to which it belonged. With independent segregation, progeny classes should have the genotypes indicated. Colours were directly inferred from the phenotypes in $A a U u$ and in $A(A, a) u u$ classes. The $A A U u$ are typical uniforms with attenuation of epistasis over $C$ alleles. Results are reasonably in agreement with expectation for all the 13 classes distinguished. Agreement with expectation is good $(\mathrm{P}=0.73)$ considering the main four groups in segregation, corresponding to genotypes $A A A u$ and $A a U u$, without bands due to $U$, plus $A(A, a) u u M^{0} M^{4}$ and $A(A, a) u u M^{1} M^{4}$, respectively with very weakly pigmented bands due to $M^{0}$ and medium to weakly pigmented bands due to $M^{1} M^{4}$.

Mating 409 is similarly interpretable. A uniform albino, progeny of 249, was mated to an unbanded red-brown (line C.IV), three main groups of classes segregating in the progeny: $A a U u$ uniforms, $A a u u M^{0}\left(M^{1}, M^{2}\right)$ unbanded, and $A$ auu $M^{1}\left(M^{1}, M^{2}\right)$ with very weakly pigmented bands. The alleles $M^{1} M^{2}$ attributed to the albino parent are inferred from this result observed in the progeny; such a genotype could be possible since some weakly to medium pigmented bands segregated jointly with strongly pigmented bands in the banded progeny of 249. Further results, which are being obtained in progeny sib matings in continuation of mating 409 as also of 407 , will provide independent evidence on $M$ alleles present in the uniform parents of both matings. Numerical results for all the 12 scored progeny classes of 409 agree well with the proposed genotypes and interpretation (for the three main groups, $P=0.62$ ).

As they stand, the results of crosses 407 and 409 support the conclusion that the $M$ locus, over which $U$ is epistatic, is not linked to this latter, but further evidence on relations between the two loci is being obtained, making use of the effect of $a$ on $U$ that makes it possible to characterise uniform classes more surely.

It may be noted that in the progeny of both crosses 407 and 409 one albino appeared which must have been a mutant. These two albinos, with typical hyalozonate bands and which died before becoming adults, were included in the mutants referred to in section 3.

\section{Conclusions on albino efFects}

Effects of albino are exerted mainly on ground shell colour and band pigmentation. The first albinos genetically studied (Stelfox, 1915, 1918; Diver, cf. Cook, 1969) were hyalozonate and it is often supposed that this is a general characteristic of albinos. The two albino founders of line A.I were one of them $\left(P_{1}\right.$ of mating 53 ) hyalozonate, with bands almost entirely translucent but acquiring a slight orange tinge near their end, the other did not show bands. Throughout this paper we refer to several types of banding 
in albinos. Absence of bands is determined in these as in pigmented by the two loci, $U$ suppressor of all types of band and $M^{0}$ for zero or almost zero intensity of band pigmentation. The foundation albino without bands should have $M^{0}$ or $M^{1}$ in its genotype. Other characteristics of bands, number, degree of fusion, band type as to width and margin sharpness or diffusion, and early or delayed banding as also the presence or absence of juvenile bands, may be expressed in albinos as in pigmented (Albuquerque de Matos, 1982 and in preparation), but in general there is a tendency for albinos to show incomplete penetrance in the effects of these factors, so that the fraction of unbanded albinos in a progeny tends to be higher than that of the pigmented sibs with the same banding factors in their genotypes. Attempts to distinguish $a$ factors resulting from distinct mutations through their effects on banding have as yet failed (Albuquerque de Matos, unpublished). Homozygous albino has an effect on darker upper part of the shell, determined by the factor $S$, similar to that exerted on band pigmentation. When $S$ is present in albinos, the upper part of the shell may be entirely translucent or more or less orange coloured. The fascia albata is not sensibly affected by the albino condition.

Each of these effects on bands and on darker upper part of the shell is completely absent in $A a$ genotypes, so that heterozygous albinos are indistinguishable as to these characters from homozygous $A A$. The same is true of the effects of $a$ on all $C$ alleles for shell colour. The only exception we have noted as to complete recessivity of the effect of $a$ alleles tested concerns $U$. Homozygous $a a U(U, u)$ are albinos with the typical effects of $U$ on shell structure and bands, and of aa on ground pigmentation; heterozygous $\operatorname{Aa} U(U, u)$ are similar to homozygous $A A U(U, u)$ or $\operatorname{aa} U(U, u)$ as to effects on shell structure and bands, but an effect is exerted by $A a$ on pigmentation determined by $U$. The reddish component of this pigmentation and, less markedly, the brown component are attenuated, more in the case of $A a U u$ than of $A a U U$, so that the colour due to $C$ alleles present in the genotype may become apparent. This observation supports the view that the affected components of the pigmentation due to $U$ are different in nature from the corresponding components (red and brown) determined by $C$ alleles. It remains to be studied how the effects of $a$ on the realisation of $U$ pigmentation are exerted.

Acknowledgements. I am grateful to Professor J. A. Serra for help in the interpretation of results. Thanks are also due to Junta Nacional dos Produtos Pecuários, Lisbon, for support of the work made in the Centro de Genética e Biologia Molecular.

\section{REFERENCES}

Albuquerque de MAtos, R. M. 1979. Genética de alguns caracteres de Helix aspersa. Portug. Acta Biol., A, 15, 99-133.

ALBUQUERQUE DE MATOS, R. M. 1982. Interaccão génica em caracteres pigmentares de Helix aspersa. Portug. Acta Biol., A, 17, 37-85.

AlbuQUerque de MATOS, R. M. 1984. Genetics of shell ground colour in Helix aspersa. I. Colour locus, uniform and their interactions. Heredity, 53, 11-20.

AlbuQUerQUe DE MATOS, R. M. Albinism and its genetics in Helix aspersa. To be published. ALBUQUERQUE DE MATOS, R. M. AND SERRA, J. A. 1982. Mutacões simples, correlacionadas e trepcoes na espécie polimórfica Helix aspersa. Portug. Acta Biol, A, 17, 87-135. 
CLARKE, B., ARTHUR, W., HORSLEY, D. T. AND PARKIN, D. T. 1978. Genetic variation and natural selection in pulmonate molluscs. In Fretter, V. and Peake, J. (eds.) Pulmonates, vol. 2A, Academic Press, London, pp. 219-270.

COOK, L. M. 1969. Results of breeding experiments of Diver and Stelfox on Helix aspersa. Proc. malac. Soc. Lond., 38, 351-358.

MurRAY, J. 1975. The genetics of Mollusca. In King, R. C. (ed.) Handbook of Genetics, vol. 3, Plenum Press, New York, pp. 3-31.

STELFOX, A. W. 1915. A cross between typical Helix aspersa and var. exalbida: its results and lessons. J. Conchol., 14, 293-295.

STELFOX, A. W. 1918, Researches into the hereditary characters of some of our British Mollusca. J. Conchol., 15, 268-275. 